\title{
¿Mujeres verdaderas o máscaras de la feminidad? Personajes femeninos en la obra de Sándor Márai
}

RESUMEN: Se pretende explorar brevemente la naturaleza femenina en la obra de Márai. PALABRAS CLAVE: Disfraz, feminidad, máscara, Sándor Márai.
SUMMARY: Female nature is briefly explored through Sándor Márai's literary work.

KEY WORDS: Disguise, femininity, mask, Sándor Márai.

Este trabajo pretende explorar sucintamente la naturaleza femenina a través de tres personajes de la obra literaria de Sándor Márai: Francesca en La amante de Bolzano, Marika en La mujer justa y Eszter en La herencia de Eszter. La feminidad que encarnan estas tres heroínas cumple con los criterios más nobles y abnegados. Los mismos que les obliga a vivir, debido a la devoción que profesan a sus respectivos objetos de amor, el mayor sufrimiento imaginable. Son personajes que albergan lo más frágil que pueda existir: un amor a prueba de todo, alojado en un cuerpo y un alma a punto de romperse.

Esa fragilidad se revela en sentimientos ambivalentes. Tan misteriosos e ilimitados como lo parece la propia feminidad. Tan sublimes, a la vez, que escapan al observador más agudo. Se pierden sin dejar huella cuando crees haber comprendido por fin la esencia de los mismos. ¿Será real esta debilidad? Aquel deseo por ser dominada, por entregarle absolutamente todo al hombre amado e idolatrado, ¿será una forma de profesar su característica más femenina o, al revés, reflejará un deseo inconsciente de dominio y de posesión de las riendas de su vida y la de quien pretende dominarla?

En la Feminidad como máscara, Joan Rivière intenta demostrar que las mujeres que aspiran a una cierta masculinidad pueden adoptar la máscara de la feminidad para alejar la angustia y evitar así la venganza que temen por parte del hombre. De este modo, intentan ser masculinas pero sin aparentarlo (1).

\section{La feminidad: el don de tres mujeres}

Dos hombres dominantes y una mujer en medio, aparentemente impotente, persisten en una relación imborrable a lo largo del tiempo. La amante de Bolzano de Sándor Márai es la versión que ha escogido sobre el personaje de Giacomo Casanova. Éste se encuentra refugiado en Bolzano, donde vive Francesca, la única mujer que ha amado en toda su vida y que no ha logrado poseer. La perdió varios 
años antes, en un duelo con el Conde de Parma, y ahora se vuelven a encontrar. Francesca es una mujer inteligente, que sabe explotar su feminidad al máximo. De esto es muy consciente: «No puedo ir con tanta belleza por el mundo sin ser castigada por ello» (2).

Una tarde, en una elegante cafetería de Budapest, Marika le relata a una amiga su vida al lado de su ex marido. Muy enamorada y entregada a éste, una de las dos mujeres principales de La mujer justa, cuenta cómo descubre que su marido no le pertenecía realmente y, a pesar de esto, intenta aferrarse y mantenerse a su lado. «Ahora pensarás que soy una histérica. No, querida, soy una mujer... una santa y una espía cuando se trata del hombre al que amo. No me avergüenzo de ello... ésa es mi misión en la vida...» (3).

En La herencia de Eszter, la historia se desarrolla en la casa de la protagonista, una mujer soltera de mediana edad y enamorada del hombre que le quitó todo lo que poseía para casarse con su hermana. Después de veinte años de ausencia, Lajos regresa a la casa de Eszter, demostrando que lo que se deja sin terminar en el pasado puede retomarse, en el presente, siguiendo el curso de su propio destino. «No puedo saber qué más tiene Dios previsto para mí. Sin embargo, antes de morir, quisiera poner por escrito el relato del día en que Lajos vino a verme, por última vez, para despojarme de todos mis bienes» (4).

De este modo, la feminidad podía ser asumida por nuestras protagonistas como una máscara que les permitiría disimular la existencia de cierta masculinidad interna y evitar las represalias temidas si llegaban a ser descubiertas. El papel doméstico de la perfecta ama de casa o de la mujer sufriente que sólo intenta repetir el rol aprendido en la infancia, representaría el mejor disfraz para una mujer ambiciosa, como si tras esa máscara de inocencia pudiesen borrar las consecuencias de sus actos y asegurar su ingenuidad (1).

Pero acaso esta ingenuidad no sea otra cosa que una manifestación de poder. Quizá resulte imposible determinar si este modo de conducirse por la vida es algo natural o un simple disfraz. No se pretende argumentar una cosa en oposición a la otra sino explorar esta posibilidad. Pues, ¿cómo podemos distinguir la feminidad verdadera del simple disfraz? Joan Rivière sostiene que tal diferencia no existe. La feminidad, esencial o superficial, coinciden. La feminidad fue utilizada como un medio para evitar la angustia, antes que como un modo primario de relación sexual.

\section{Tras los pasos de la feminidad}

En la vida real, tanto como en la literatura o el resto de las artes, la máscara de la feminidad puede adoptar los aspectos más curiosos. La exploración de la 
naturaleza humana, en lo que se refiere a las diferencias sexuales, constituye una lucha entre fuerzas potencialmente iguales, donde cada uno hace gala de sus armas más poderosas para explorar en qué consiste eso de ser masculino o femenino.

En el Banquete de Platón, Aristófanes menciona la importancia que encarna conocer la naturaleza humana y las modificaciones que ha sufrido. «Tres eran los sexos de las personas, no dos, como ahora... El andrógino era entonces una cosa sola... que participaba... de lo masculino y de lo femenino...». Castigados por Zeus, quien los corta por la mitad para hacerlos más débiles y más útiles a los dioses, los andróginos morían añorando cada uno su propia mitad. «... El amor de los unos a los otros es innato en los hombres y restaurador de la antigua naturaleza... Por esta razón, precisamente, cada uno está buscando siempre su propio símbolo...», intentando, de este modo, poner remedio a la fragilidad humana $(5 ; 6)$. Tanto lo masculino como lo femenino provendrían de un molde roto que intentará fusionarse de nuevo.

Eros -restaurador y conciliador de los seres divididos- actuaría de formas muy complicadas y difíciles de entender. Pues, aprovechando una apariencia ambigua y huidiza, se refugiaría también en una máscara que le permitiría representar aquello que no es. Eros mismo, por el hecho de buscar la belleza en todo, delataba aquello que no tenía: «Desea aquello de lo que está falto y no lo desea si no está falto de ello» $(5 ; 6)$. Desde tiempos remotos, por consiguiente, se aprecia la dificultad para determinar lo masculino y lo femenino, porque bajo las apariencias se esconde algo completamente distinto.

La feminidad nacería, ya desde la Antigüedad, de una unidad completa, y acompañaría a la masculinidad como un equivalente imprescindible. Desde aquellos tiempos se observa que lo que antes era claro y blanco puede ser más turbio y negro de lo que se cree. Eros, en cuanto que buscador de la belleza, tiene mucho de femenino en sí. Está sediento por algo que no tiene pero que intentará poseer, actuando del mismo modo que lo hacen los tres personajes enmascarados de Márai.

\section{Por las huellas del complejo de Edipo}

En 1927, el artículo de Ernst Jones titulado «El desarrollo temprano de la sexualidad femenina» plantea si una mujer nace o se hace, dada la asimetría de la fase fálica, y otorga un lugar preponderante a las fases más arcaicas de la sexualidad en la cual la castración es sólo una amenaza parcial para ambos sexos. El miedo a la castración en el hombre sería como el miedo a la separación o al abandono en la mujer. Jones halla una angustia primaria relativa a los dos: el miedo a 
una extinción total del deseo, denominada afánisis o desaparición $(1 ; 7 ; 8)$. La fase fálica tendría, en la mujer, un carácter defensivo y secundario con respecto a la afánisis del deseo (8).

Así como el niño debe elegir entre su madre o su virilidad, la niña deberá abandonar su nexo erótico con el padre o su feminidad. Debe cambiar de objeto o de deseo pero no conservar ambos. Por lo tanto, confrontados con la afánisis -resultante de una privación inevitable-, ambos sexos deben renunciar a su incesto o a su identidad $(1 ; 9-10)$.

Jones y Horney concentraron su estudio en la naturaleza de la mujer, y negaron su adhesión a la fórmula de Freud según la cual la feminidad se adquiere a través de sucesivas renuncias a rasgos masculinos. Jones quiere demostrar, de este modo, que la niña es una mujer en potencia y no un pequeño varoncito $(11 ; 12)$.

Saphouan, por su parte, considera que estas ideas son insuficientes, pues caen en la paradoja de querer encontrar un equivalente a la castración, y que ese deber elegir del que habla Jones entre el objeto incestuoso y su sexo, desde la visión de la afánisis en el Edipo, no es tal, porque en la estructura de la neurosis la pérdida del objeto incestuoso quedaría asegurada. En la mujer, el miedo a la destrucción como represalia de la propia madre rival la empujaría hacia el falicismo y no hacia la afánisis (7). «Cuando mi marido y yo nos divorciamos, no pensé ni por un instante que pudiéramos quedar como 'amigos' ... yo no fui ni educada ni generosa, me llevé hasta el piano, sí, como tiene que ser. Anhelaba venganza... me convertí en su enemiga en el momento del divorcio y lo seguiré siendo hasta el día de mi muerte... Juré venganza de otro modo, no con la razón sino con los sentimientos», dice Marika en La mujer justa (3).

La diferencia sexual nos lleva a la formulación de la pregunta sobre quién manda y quién está subordinado, dado que es imposible anular las relaciones de poder que acompañan a las diferencias. La duda más inquietante descansa en la posibilidad de que toda diferencia obligue a una masculinidad obligatoria (13).

Marika palpa con impotencia las diferencias con su marido y el sufrimiento que su inferioridad conlleva. «Comprendí que mi marido, a quien creía mío por completo, a quien, como se suele decir, creía conocer en cuerpo y alma... no me pertenecía... ¿dime, qué es el poder... cuál es el fundamento de nuestro poder, el de las mujeres? El amor, dices. Puede que sea el amor. A veces dudo de esa palabra... Sin embargo, a veces siento que cuando los hombres nos aman, porque no pueden hacer otra cosa, al mismo tiempo desprecian un poco ese sentimiento...» (3). Recuerda también estas palabras de su marido: «Hay hombres de naturaleza más femenina que necesitan precisamente eso, ser amados. Pero hay otro tipo de hombres que, como mucho, toleran el amor. Yo soy uno de ellos» (3). 
En el fondo, elegimos a alguien a quien desear bajo la pretensión de que nos desee a nosotros por encima de los demás (13). Comenta Marika sobre su ex marido en La mujer justa: «Interiormente, no lo dejé libre ni por un momento. Lo mantenía a mi lado por medio del niño, lo chantajeaba sin palabras con mi exigencia emocional... Dedicaba al niño cada segundo de mi vida, pero sólo porque sabía que, mientras estuviera el niño, estaría él y sería sólo mío...» (3).

La mujer, no insertada en la lógica de la castración, tiene un inconsciente «sólo desde donde la ve el hombre» y deja el suyo en un extraño suspenso. De acuerdo con Miller, obtener placer con el sufrimiento, como Freud imputaba a la mujer, es como decir que la mujer es susceptible de un mayor placer que el hombre. En cierto modo, el sexo fuerte -en lo que al goce se refiere- es femenino. Para Lacan, la posición femenina es «positiva» porque se posiciona en el goce y, para Freud, es «negativa» porque lo hace desde la libido (14-18).

En La amante de Bolzano, es dudoso que Francesca sea consciente de su manera de actuar en todo momento y de la ambigüedad de su discurso. En él ratifica lo mucho que ama al tiempo que odia a Casanova, con un conocimiento que le es propio y ajeno a la vez. Bajo esa belleza y docilidad se esconde una mujer muy fuerte que ha sido el objeto de un infinito duelo a muerte. «Fuiste cobarde, y ése es un pecado muy grave. Pero yo te perdono todo, incluso lo que el mundo es incapaz de perdonarte; te perdono tu carácter y tus debilidades, tus inclinaciones crueles y tu egolatría incontrolada... Has de entender, amor mío, que no pronuncio las palabras 'te amo' ni con ternura ni con ilusión. No, más bien las pronuncio con ira, gritándolas, echándotelas en cara, como si fueran una acusación o una orden» (2).

\section{¿Acaso soy una perversa?}

Según la hipótesis de Louise Kaplan en Perversiones femeninas (Las tentaciones de Emma Bovary), los prototipos de ideas infantiles de la feminidad, como la pasividad, la limpieza, la pureza, la bondad, la preocupación por los demás o la sumisión serían un reflejo de que las mujeres aprenden rápidamente a disfrazar su capacidad intelectual de intuición femenina, y a convertir sus deseos sexuales activos en coqueteos y en una inaccesibilidad sexual. Para la autora, si las perversiones masculinas se manifiestan con actos sexuales prohibidos que imitan y caricaturizan la práctica genital adulta, las femeninas se manifestarán en conductas que imiten y caricaturicen un ideal femenino (19).

Con respecto al fetichismo, Freud decía que la explicación analítica en cuanto al sentido y al propósito del fetiche era siempre el mismo. No es el sustituto de 
un pene cualquiera sino de aquel que tuvo mucha importancia en la niñez y se perdió: el falo de la madre. La función del fetiche es ser el emblema del triunfo sobre la amenaza de castración para, de este modo, volver a la mujer aceptable como objeto sexual (20).

La perversión se debe contemplar como una estrategia psicológica inconsciente cuyo aspecto crucial es engañar al espectador sobre el significado inconsciente de las conductas que observa. Nadie, ni siquiera el propio sujeto, puede imaginar sus terribles secretos.

En la perversión masculina existe el miedo a los propios deseos femeninos. Existe un temor de destructibilidad ante cualquier cuerpo que represente para el perverso las debilidades y la feminidad que desprecia y teme en sí mismo. La mujer, como máscara de la feminidad, percibiría con claridad este factor. Al igual que sucede con los fetiches del varón, si la mujer estima que sus poderes intelectuales y sexuales son trofeos fálicos que se le pueden robar, hará cuanto pueda por engañar al mundo y hacerse pasar por un sujeto absolutamente femenino, desvalido, pasivo y sufriente. Como el orden social determina cuáles son las virtudes femeninas que hacen a una mujer deseable y valiosa, cualquier resultado supuestamente normal puede ser un subterfugio perverso (19).

¿La casa de Eszter representaría un trofeo fálico o, acaso, el amor de Lajos? Eszter había logrado sobrevivir, difícilmente, a los engaños de Lajos, un hombre cruel, mentiroso y sin escrúpulos del cual había estado enamorada. Había conservado como única herencia de su padre una casa que se caía a pedazos. Resulta difícil entender cómo una persona puede caer, de esa forma, en el engaño de un hombre que conoce a la perfección. Pero, no se trata simplemente de caer en él, sino de ser quien ejecute su propia sentencia: «Sí, yo veía más allá de su fachada, me daba cuenta de cómo era y, sin embargo, estaba dispuesta a servirle de una manera ciega y ansiosa...» (4).

Por un lado, estaba el deseo de que hubiese cambiado y viniese a cumplir sus promesas y a pagar sus deudas, pero, por otro, antes de que se produjera el encuentro, Eszter entendió que no era ese el motivo. Tenía que llevarse lo único que no pudo: la casa. Lajos está tan engañado por su narcisismo y por la ingenuidad que no logra ver la inteligencia ni el poder de Eszter. La desprecia trayendo a su casa a otra mujer, pidiéndole que le dé, en colusión con esta otra, el único bien que le queda para subsistir. Piensa jugar una partida con ventaja. No se da cuenta que esta mujer, menospreciada por él, lo comprende todo y está un paso más allá de lo que se pueda llegar a entender con facilidad.

La satisfacción que ella encuentra al adoptar una posición totalmente pasiva y femenina es fácil de descifrar si logramos ver que es, precisamente, el modelo perfecto de la máscara de la feminidad. Inconscientemente, ella le ha ganado la 
batalla a Lajos. Se ha quedado sin nada. Sabe que esa nada, decadente y funesta, será peor de lo que el propio Lajos imagina y pueda entender. Le llevará no sólo a la miseria sino a su muerte, previsible sólo por ella. Este conocimiento es el trofeo fálico de Eszter y no el trofeo de su casa.

\section{¿Serán todas esclavas del amor?}

Los tres personajes descritos de los libros de Márai no se atreven a exigir lo que desean. Actúan en provecho de un abismo por el cual sienten fascinación. Apuntan a un sacrificio que busca el aniquilamiento. ¿Eszter quiere retener a Lajos o quiere que se vaya? ¿Francesca quiere fugarse con Casanova o seguir siendo la Condesa de Parma? ¿Marika quiere recuperar a su marido o encontrarle a su amante perdida? Este goce suplementario en ellas queda fuera del discurso. Las tres llegan a ser lo que no tienen sólo como compensación (15).

Los estereotipos son aspectos centrales de la estrategia perversa. Francesca, Ezster y Marika se convirtieron en esclavas del amor. Hay una renuncia al modelo convencional sólo para adquirir otro. Un deseo de obedecer al hombre en todo lo que éste quiera, enmascarando las reales intenciones que las animan. Algo que parece ser bastante común en las actividades de ciertas mujeres cuando sobreviven a la adoración abyecta de los hombres. Les lleva tiempo reconocer que buscan su tormento con empeño, que tienen que degradarse y permanecer en un estado de sometimiento humillante para que el amante conserve su posición de dominio (19). «Naturalmente, todos sabíamos que Lajos quería apropiarse de mi vida... y de la tranquilidad de mis últimos años. Sólo nos quedaba la casa, un poco ajada por el paso del tiempo, pero poderosa en todos los sentidos: la casa, el último objeto de valor que Lajos no había podido llevarse y que aquel día había venido a buscar» (4).

Cuando está separada de su amante, la esclava del amor se siente vacía e inexistente. Mientras lo espera, prepara su cuerpo para éste; se queja y se jacta de él al mismo tiempo. Finalmente, se reúnen y se restituye el sentimiento de estar viva (19).

Marika, en La mujer justa, descubre no sólo que su marido no la ama, sino que está secretamente enamorado de otra mujer. Durante años, la verdadera mujer ante los ojos de éste ha sido la criada de la casa de su suegra. Va a verla una mañana y lo descubre todo. Lo comenta con su amiga durante la charla en el café: «Veo que no acabas de comprender todo esto. Si lo pienso bien, yo tampoco lo comprendo del todo. Pero entonces me pareció todo tan natural... Estaba de pie en el cuarto de la criada de mi suegra, jurando a una sirvienta que nunca revelaría a mi 
esposo lo que iba a oír. ¿Una cosa así te parece natural? Yo creo que sí... Llevaban doce años callados, así de simple. Y, mientras tanto, ella llevaba al cuello la fotografía de él en un medallón mientras él atesoraba el trozo de cinta cortada del medallón en el compartimento secreto de su cartera... Si él no ha sabido tomar una decisión en doce años, la tomaré yo por él en mucho menos tiempo. Si él no sabe encontrar a la mujer justa, la encontraré yo por él...» (3).

Las prácticas perversas tienen que ver con necesidades desesperadas que explican la razón por la cual una mujer tolera esas condiciones. La compulsión a repetir un trauma es, decisivamente, más poderosa que la búsqueda del placer y la evitación del dolor. La amenaza de abandono se yergue como un ingrediente esencial en la perversión, a la que aporta un componente muy femenino (19).

En La amante de Bolzano, es Francesca y el papel que desempeña al final del libro lo que quizá llame más la atención. Durante los capítulos previos al encuentro se han ido elaborando los elementos necesarios para recorrer el camino de este desenlace. Se encuentra rendida al poder de tan poderoso amante, ante quien resulta inútil resistirse. «Soy una mujer, aunque esté disfrazada de hombre, una mujer que sabe algo con total seguridad y que actúa en consecuencia... Si quieres humillarme, Giacomo, no podrás inventar una manera de hacerlo que no me guste, porque te amo... me preocuparé por inventar nuevos suplicios para que tu placer sea aún mayor y más verdadero» (2). Sin embargo, Francesca también puede ser completamente distinta. Muy joven y representando un papel femenino marcadamente pasivo -al lado de un hombre mayor y poderoso -hará gala de su más absoluta inteligencia, sobre la cual existen motivos para dudar si está convencida o no de poseer tan valiosa arma. «Pero si prefieres que te domine yo a ti, seré cruel e insensible contigo... conozco los secretos del amor... de la ternura y la tortura, los secretos estimuladores del cuerpo y del alma, los secretos de los elíxires y de la lencería femenina, los secretos de la iluminación apropiada para el amor, de los perfumes y las caricias y también de la abstinencia... Tengo que saber qué deseas tanto como para no confesártelo ni a ti mismo...» (2).

Algunas mujeres extraen placer de la derrota y toman venganza, convirtiendo su pequeña perversión en un triunfo. Un acto de venganza contra aquellas personas que le dieron amor y luego se lo quitaron. «En todo ser humano adulto hay una perversión al acecho en sus transacciones neuróticas y en sus actitudes llamadas normales», dice Kaplan (19).

Si una mujer siente que no puede sobrevivir a menos que se pegue a un ser fálico idealizado, tarde o temprano experimentará resentimiento y envidia por su poder. Cuando tome conciencia de ello, habrá momentos de ira, tal y como cuando Francesca le grita las palabras «te amo» a Casanova. Ella coopera con este 
hombre porque un modo de mantener a un tirano en su poder es imaginando que podría escoger a otra esclava.

El aimer d'amour es amar con el amor de darse totalmente. La mayoría de las esclavas del amor sucumben a ese romanticismo perverso que las deja sin energías para salir de la situación. Las tres heroínas mencionadas de Márai: Francesca, Marika y Eszter son verdaderos iconos y abanderadas de este aimer d'amour. La extraordinaria entrega romántica del enamoramiento común que estos personajes vierten en sus hombres, se convierte en una perversión al perfilar el sentimiento de la propia insignificancia frente a la magnificencia del amado. «Si la esclava paga entregando su alma al amo, puede continuar con sus ocupaciones prohibidas hasta que llegue la siguiente factura». Una ocupación prohibida es la sexualidad y, otra, la ambición intelectual. Esta última convierte su derrota en victoria y la victoria del amo en derrota (19). Francesca ha madurado y ha aprendido a amar. Se ha superado en muchos aspectos aunque sigue atada a un hombre que no ama y anhelando un futuro que jamás llegará a posicionarse.

Hay otras, como Eszter, que evocan pena y hasta rabia por la postura que adoptan. Se muestra como una insignia de amor, como una excepción, como alguien especial cuya obediencia anula las órdenes del amo. La enorgullece más su sufrimiento autoinflingido que el orgullo que pueda sentir el hombre por abusar de su aimer d'amour. La pérdida de su casa se convierte en un triunfo fálico porque la hace más importante y más poderosa. Se la han intentado quitar, pero es ella quien ha decidido entregarla como una donación que le permite gozar de un modo inesperado (¿o mejor incomprensible?).

\section{Epílogo}

Efectivamente, nos hemos estado preguntando si estas mujeres representan disfraces de feminidad mientras se revelan como consumadas estrategas. La máscara de la feminidad ha resultado un disfraz tanto de apariencia externa como inconsciente: la perversión les permite acceder a situaciones elementales que les resultaría imposible soportar de otra manera. Todo lo cual nos obliga a pensar en una regla básica: que las perversiones nunca tienen que tomarse por lo que parecen (19).

El enigma que representa la mujer para el hombre vuelve a estar vivo y no encaja en el goce del varón. Francesca, Marika y Eszter se yerguen como tres enigmas, tres personajes que son creados para compartir un modelo de historia que refleja la más pura esencia de un modo de entender la feminidad. Mujeres creadas por la pluma de un hombre que parece comprender muy bien el mundo de las 
mujeres, en cuanto que relativas al hombre, lo que viene a mostrar que no se sabe nada ni de los unos ni de las otras.

¿Qué es una mujer? ¿Es un disfraz, una estratega perversa, una máscara de sufrimiento? ¿No es nada de esto o lo es todo a la vez? En resumen: ¿Qué quiere la mujer?

\section{BIBLIOGRAFÍA}

(1) Rivière, J., y otros, La femineidad como máscara, Barcelona, Tusquets, 1979.

(2) MÁraI, S., La amante de Bolzano, Barcelona, Salamandra, 2003.

(3) MÁRAI, S., La mujer justa, Barcelona, Salamandra, 2005.

(4) MÁrai, S., La herencia de Eszter, Barcelona, Salamandra, 2006.

(5) Platón, «Banquete» en Diálogos III, Madrid, Gredos, 1986.

(6) Ferrand, J., La melancolía erótica, Madrid, AEN, 1996. 1979.

(7) Saphouan, M., La sexualidad femenina según la doctrina freudiana, Barcelona, Crítica,

(8) Jones, E., Obras escogidas, Barcelona, RBA, 2006.

(9) FREUD, S., «La organización genital infantil», Obras completas IV, Barcelona, RBA, 2006.

(10) Freud, S., «La disolución del complejo de Edipo», Obras completas IV, Barcelona, RBA, 2006.

(11) GAY, P., Freud. Una vida de nuestro tiempo, Barcelona, Paidós, 1996.

(12) FreUd, S., «Sobre la sexualidad femenina», Obras completas IV, Barcelona, RBA, 2006.

(13) Colina, F., Deseo sobre deseo, Valladolid, Cuatro Ediciones, 2006.

(14) FreUd, S., «Algunas consecuencias psíquicas de la diferencia sexual anatómica», Obras completas IV, Barcelona, RBA, 2006.

(15) Miller, J. A., Introducción a la clínica lacaniana. Conferencias en España, Barcelona, RBA, 2006.

(16) Soler, C., Lo que Lacan dijo de las mujeres, Buenos Aires, Paidós, 2006.

(17) Állvarez, J. M.; Esteban, R.; Sauvagnat, F., Fundamentos de psicopatología psicoanalítica, Madrid, Síntesis, 2004.

(18) Lacan, J., Seminario V. Las formaciones del inconsciente, Buenos Aires, Paidós, 2004.

(19) Kaplan, L., Perversiones femeninas. Las tentaciones de Emma Bovary, Buenos Aires, Paidós, 1994.

(20) FreUd, S., «Fetichismo», Obras completas IV, Barcelona, RBA, 2006.

* Francisco Vaccari, MIR de Psiquiatría del Hospital Universitario del Río Hortega de Valladolid. Correspondencia: C/ Orión 2, 47014 Valladolid. franjov@yahoo.com

** Fecha de recepción: 10-XI-2007 (aceptado el 25-IV-2008). 